\title{
Initiatives for Change in Korean Higher Education: Quest for Excellence of World-Class Universities
}

\author{
Jean S. Kang ${ }^{1}$ \\ ${ }^{1}$ Division of International Studies, Scranton College, Ewha Womans University, Seoul, Republic of Korea \\ Correspondence: Jean S. Kang, Division of International Studies, Scranton College, Ewha Womans University, \\ Seoul, Republic of Korea. Tel: 82-2-3277-3354. E-mail: jskang@ewha.ac.kr
}

Received: March 3, 2015 Accepted: April 5, 2015 Online Published: June 29, 2015

doi:10.5539/ies.v8n7p169 URL: http://dx.doi.org/10.5539/ies.v8n7p169

\begin{abstract}
The establishment of World-Class Universities (WCUs) is noted as a paramount development in the realm of international higher education. The integration of higher education into a more international scheme has enabled for higher education institutions (HEIs) to have a broader impact on the states and their respective citizens. This study examines the current environment of the higher education system, as well as the important factors that have contributed to placing WCUs at the center of international higher education policies. In particular, this study will analyze the policies and practices of the Republic of Korea that have been created to establish globally competitive HEIs. The Brain Korea 21 Projects, the WCU Project, and global rankings have contributed to the nation's ongoing quest for excellence in tertiary education. As HEIs in Korea continuously enhance their international status in the field of higher education, it becomes increasingly important to review and provide insights on globally competitive institutions as well as higher education reforms that have been applied to Korean universities.
\end{abstract}

Keywords: higher education, world-class universities, tertiary reform, internationalization

\section{Introduction: Knowledge and Higher Education}

The importance of higher education was first acknowledged at the 1998 UNESCO World Conference on Higher Education, where representatives from 182 different states examined the prospects of higher education in context of the 21st century (United Nations Educational, Scientific and Cultural Organization [UNESCO], 1998). The conference identified higher education institutions (HEIs) as effective agents not only for the development of the intellectual society, but also for that of national power and the global economy. After the extensive potential of higher education was recognized with respect to globalization, the transnational exchange of higher education was also promoted through the integration of internationalized indicators into the overall educational framework. For instance, the ranking system of universities worldwide constituted one of the primary indicators of development and achievement in the domain of higher education, and the notion of "World-Class Universities" (WCUs) emerged on the global front of tertiary education.

The concept of WCUs has become widely known, yet it remains highly ambiguous. Though various countries have contributed to the creation of WCUs, they have failed to establish a common consensus as to how a "world-class university" should be classified; as Altbach (2004) states, "everyone wants one, no one knows what it is, and no one knows how to get one." Yet, there still exist basic requirements and necessary criteria that tertiary institutions need to satisfy in order to be designated as a WCU. According to Altbach (2004), a WCU requires the following: excellence in research, academic freedom, an atmosphere of intellectual excitement, appropriate governance of the institution, adequate facilities for academic work, and adequate long-term funding. Salmi (2009) further denotes three commonly identified attributes of WCUs: (a) high concentrations of talent (faculty and students), (b) abundant resources that create a rich learning environment which allows for the conduct of advanced research, and (c) favorable governance features that encourage strategic vision, innovation, and flexibility that enable institutions to make decisions and manage resources without bureaucratic complications. The ranking systems for world universities also reflect the various criteria that should be satisfied in order for an institution to be designated as a WCU. Yet, due to the lack of systematic methods for judging the multiple criteria, the overall evaluation process for WCUs is susceptible to subjectivity. However, WCUs are still generally regarded as the epitome of academic excellence with respect to their overall achievements and high 
institutional standing.

\section{Method}

To examine the recent changes in the realm of international higher education and the initiatives that the Korean government has taken to enhance its global status in higher education, this paper incorporates concepts and perspectives of previous studies through an extensive literature review and investigation of institutional documentation at both national and international levels. A qualitative evaluation of Korea's trajectory in the field of higher education from the mid-1990s will shed light on various perspectives related to fundamental notions of excellence in higher education, especially, with regard to the results of national projects that have culminated differing outcomes. This study will conclude with insights and recommendations on the future course of Korea's endeavor to raise its global profile in higher education.

\section{The Knowledge-Based Economy and Higher Education}

The transformation within the domain of higher education - as observed by the establishment and promotion of globally-ranked HEIs - has prompted inordinate global interest. The major forces that have brought upon such transformation are categorized into three factors: the emergence of a knowledge-based economy, internationalization, and the increased demand for public accountability and transparency.

The emergence of a knowledge-based economy has established "knowledge" as the foundation of economic, social and political power; "knowledge is defined as [an] intellectual property (IP) that has commercial value (which) can be realized, in turn creating economic value and thus economic growth" (Robertson, 2005). Hence, within a knowledge-based economic setting, the nation's wealth production focuses on generating intellectual assets instead of accommodating for the overall productivity and efficiency. "The World Development Report on Knowledge for Development, 1998-1999" introduced four strategic dimensions of a knowledge-based economy: "an appropriate economic and institutional regime, a strong human-capital base, a dynamic information infrastructure, and an efficient national innovation system" (Sadlak \& Cai, 2009). Within the knowledge-based economic paradigm, higher education is identified as a crucial component for creating a strong human-capital base, as well as an efficient national system geared towards innovation.

Due to the importance of intellectual assets in a knowledge-based economy, national governments have come to focus on tertiary education as the basis for creating and implementing policies (Hazelkorn, 2011). In addition, the notion, "New Public Management" (NPM), has also expanded to account for HEIs, thereby designating universities as firms that produce academic capital: knowledge gained by original and innovative research (Hood, 1989; Pollitt, 1993). Therefore, since knowledge can be seen as a form of valuable commodity generated by the university sector, governments are led to invest heavily on HEIs in order to increase economic revenue and national power (Hunt, 2011).

Higher education exhibits positive effects on both the private and public sectors of a knowledge-based economy. The private benefits include greater career opportunities, incomes, as well as savings and investments for individuals. In addition to the private benefits, the public benefits of higher education pertain to the development of the national economy, technology, as well as the overall economic outputs (Bloom, Hartley, \& Rosovsky, 2006). For instance, HEIs provide a fundamental basis for the development of human capital, which is a vital component in the national economy (Hazelkorn, 2013). Higher education also serves as a means by which one can transform his or her social and economic status. Due to such impacts that higher education can have on the economy, various stakeholders in tertiary education have transformed into savvy consumers who weigh the costs and benefits of new initiatives and programs related to educational institutions. As a result, the ranking systems of global universities have accommodated to such needs of stakeholders by attempting to provide a standard ranking of universities which is rightly or wrongly deemed to correspond with the strengths of the respective national economies of the different universities.

Internationalization has also fueled a series of strategic changes for the establishment of WCUs. Due to the increased integration of international academics into the global knowledge network, the incorporation of top students and faculty into WCUs has risen and contributed to the transnational mobility of WCUs. Since talent and innovation have become driving forces in the global economy, countries with flagship universities have identified the need to attract talented individuals and scholars from across the world (Hazelkorn, 2011). As a result, increased transnational mobility has directly promoted "international exchanges, research collaborations, the internationalization of the curriculum, the attraction of promising young scholars and international star scientists, the establishment of branch campuses abroad and the formation of international research and teaching consortia" (Hazelkorn, 2013). Internationalization has not only contributed to the mobility of top foreign students, but also that of prominent foreign faculty and researchers, as well as domestic faculty who have been 
educated abroad. In order to incorporate faculty members who have received foreign education, incentives such as flexible remuneration, various time-frames for work, favorable employment conditions are offered. Other strategies of internationalization include the formulation of "institution to institution" partnerships with HEIs in other countries. Such academic exchange networks among top institutions promote the sharing of knowledge and intellects which is mutually beneficial to all participants. In addition, an increasing number of universities have been encouraging research articles to be written in English in order to attract broader academic audiences, and consequently, international recognition (Sadlak \& Cai, 2009). In sum, internationalization has highlighted the merits and significance of WCUs along with their global rankings.

Finally, the increased demands for public accountability and transparency within the tertiary education sector have led to greater utilization of global rankings in formulating the strategic transformation of HEIs. Higher education institutions and the relevant national governments were previously unable to provide sufficient information to the consumers of knowledge. However, in order to accommodate the continued demands for institutional information regarding HEIs, the public and private sectors began utilizing evaluation measurements, such as the global university rankings. As noted by Hazelkorn (2011), "rankings have arguably and controversially become the accountability and transparency instrument by which students, especially international students, governments and other stakeholders acquire such information."

The heightened significance of HEIs is a by-product of a worldwide evolution in the higher education environment. The development of knowledge-based economies and increased internationalization have reinforced and hastened the rise of acclaimed WCUs. Meanwhile, public demand for accountability and transparency has accelerated this universal transformation by positioning global university rankings as key indicators of prestige and national power.

\section{Academic Rankings of World Universities}

Though international university rankings have a long-standing tradition worldwide, they were brought to the forefront of higher education in the 21st century. In the early 1980s, the World Bank and the Organization for Economic Cooperation and Development (OECD) made efforts to establish global statistics on indicators that could be used to compare HEIs (Robertson, 2012). The movement was further amplified in the 1990s, when the growth of tertiary education in the Asia-Pacific region led to the development of structured rankings, several of which are now recognized as leading indicators of world universities: the Academic Ranking of World Universities (ARWU) by Shanghai Jiao Tong University since 2003, the Times Higher Education Supplement World University Rankings (THES) since 2004, and the QS World University Rankings by QS Quacquarelli Symonds since 2009 (Jöns \& Hoyler, 2013). The indicators used by the THES, the ARWU, and the QS World University Rankings are similar in general, with all rankings assessing the comprehensive quality of education, faculty and research performance. However, the QS World University Rankings are considered to be more subjective as they focus heavily on institutional reputation and utilize inputs such as "peer review," whereas the ARWU and the THES rely on the more "objective" and quantifiable indicators, including publication rates and citations of authors (Sadlak \& Cai, 2009).

Despite the great impacts that global rankings have had on the higher education market and its stakeholders, the methodology of evaluation remains largely controversial. The lack of internationally accepted evaluation standards continues to undermine the reliability of global rankings. Such lack of "consistency in data definition, sets, collection, and reporting," as well as the data sources make global rankings prone to subjectivity and bias (Hazelkorn, 2013). In addition, data can be manipulated in favor of specific categories of institutions. Seemingly arbitrary selections of indicators and weightings pose serious problems and challenges to the viability of objective measurements of qualitative institutional capacities. Since the THES, the ARWU, and the QS World University Rankings prioritize research performance in comparison to the other criteria, various rankings ignore the diversity of roles and contexts of universities. As Hazelkorn (2013) notes, "no attention is given to the social and economic impact of knowledge and technology transfer, or the contribution of regional or civic engagement or 'third mission' activities to communities and student learning outcomes."

Slanted results of rankings provide collateral evidence of methodological flaws and subsequently impact the overall credibility of global rankings. Most highly-ranked universities are from English-based countries, which are often implicated in the augmentation of Western academic hegemony, particularly in the domain of technical sciences. The database offered by the Institute of Scientific Information (ISI) reinforces a Westernized perspective through its large composition of Anglo-American periodicals, provided by Thomson Reuters, a multinational mass media and information firm based in the U.S. To the extent that English remains the designated language of international academic scholarship and "subject-specific publication cultures" continue to 
be overlooked, it is claimed that such constraints will continue to reinforce Western academic hegemony (Jöns \& Hoyler, 2013).

Jöns and Hoyler (2013) further argue that global university rankings facilitate cautious interpretations of geographical power play. For instance, the concentration of WCUs in the more prosperous northern regions such as North America, Europe, and East Asia reflect the economic disparity between the global North and South. In addition, the domination of Anglo-American countries raises questions regarding the partial and biased representations of universities worldwide through the politics of inclusion and exclusion. As Amsler and Bolsmann (2012) demonstrate, rankings "have not only remained intact as strategies for the production and reproduction of social inequality...but that they have now become consolidated even more tightly in a globalised field of elite power." Due to such limitations, global university rankings are often involved in allegations of "gaming" and quantitative measurements of scholarly output are viewed as proxies for quality of scholarship. Nonetheless, international rankings continue to be scrupulously monitored by numerous stakeholders in the tertiary education market and consequently augment the growing influence of such ranking on the fostering of WCUs.

\subsection{Implications of Rankings on Higher Education Institutions}

Despite controversies surrounding the validity of the HEI ranking system, the development of WCUs and global rankings dramatically transformed the higher education industry. The heightened demand for global rankings directly correlates with the overall benefits that have accumulated to the world's top universities in terms of "international visibility, investments, recruitment and profile" (Cremonini, Westerheijden, Benneworth, \& Dauncey, 2014). Such demand for global rankings is also reflected by the results of international surveys which indicate that over $50 \%$ of higher education leaders are not satisfied with their current rank, and that more than $90 \%$ desire to improve their national or international rankings; in addition, of those who wish to improve their rank, over $60 \%$ have taken action towards such objectives (Hazelkorn, 2008).

League tables have also caused status competition among HEIs, and consequently, rivalries between stakeholders of higher education. Although the global ranking system provides a simplified analysis of the different universities as a type of "scopic system," the rankings also serve a bigger purpose as practical reference points for individuals, institutions, and national governments (Robertson, 2012). For instance, since rankings have a high influence on institutional partnerships, HEIs benchmark institutions that have higher composite scores in order to improve their overall standing. Rankings are also used by students to help choose where to study, by stakeholders to decide where to invest, and by governments to gain insights on the direction of higher education reform. The growing interest in international education at tertiary levels has also contributed to the development of various associations and theme-based conferences concerning international higher education: NAFSA: International Education Association Annual Conferences; Association of International Education Administrators (AIEA) Annual Conferences; Going Global; European Association for International Education (EAIE) Annual Conferences; and the Asia-Pacific Association for International Education (APAIE) Conferences and Exhibition with participation from regional organizations and institutions worldwide (Wit, 2012).

\section{Structural Changes in Higher Education of Korea}

Higher education and human resources have consistently constituted key interests in the Republic of Korea (Korea). Despite numerous changes in tertiary education policies, the most comprehensive reforms have been undertaken from the mid-1990s. Since then, the agenda of the leading Korean universities and government policies have both reflected the universal focus of developing effective and globally ranked HEIs.

Initial changes in the higher education structure began to take place in 1995 with the Korean government's adoption of the "May 31 Education Reform Plan," which prioritized deregulation, competition and marketization in tertiary education. In 1995, Korea also gained membership in the World Trade Organization, which motivated the nation to announce the "Initial Plan for Opening the Higher Education Market to Foreign Countries" in 1996 with the understanding that higher education had become an economic commodity that could be traded. Within the context of an emerging knowledge-based society and the "New Public Management," internationalization plans were created based on global standards and competition (Byun, 2008; Byun \& Kim, 2011).

Increasingly noticeable shifts in politics, economy and society were apparent in Korea during the Dae-Jung Kim administration (1998-2003). The primary goal of the administration focused on "the integrated development of democracy and a market economy" (Moon \& Kim, 2001). Groundbreaking reforms began to unfold in virtually all sectors. While Korea gained membership in the Organisation for Economic Cooperation and Development (OECD) in 1996, shortly thereafter, the nation confronted the Asian financial crisis and subsequently received considerable aid from the International Monetary Fund (IMF) (Moon \& Kim, 2001). The dramatic increase in 
the unemployment rate due to the economic crisis raised the awareness of education as an important criteria in the changing job market. Therefore, since 1998, the Korean government has set plans to transition to a knowledge-based economy. Along with the economic goals of providing conditions for a "market economy," the new policies of a knowledge-based economy have directly influenced the educational landscape of Korea. Initiatives to build international university campus environments, while enhancing the educational and research qualities of Korean institutions to enable the emergence of "world-class" HEIs have been heralded (Mergner, 2011). Subsequently, HEIs in Korea have flourished with greater autonomy, diversity and specialization in academic sectors, with the objective of achieving global competitiveness (Moon \& Kim, 2001).

Another important factor that has continued to effect changes in higher education revolves around the "greying of the population" (Kim, 2010). While aging of the population is considered a global phenomenon, Korea is recognized as one of the most rapidly aging societies in the world. Given the serious implications of an aging society, higher education institutions are expected to witness a steady decline in the number of matriculated students in the foreseeable future. Such consequences have propelled the Korean government to focus on both elevating the profiles and improving the quality of HEIs to successfully sustain the needed human resources for a knowledge-based economy (Lee, 2012).

Through a series of higher education reforms, numerous national projects have been initiated by the Korean government. The "Brain Korea 21 Project was first launched in 1999 and again in 2006 to establish elite research universities. The "Study Korea Project", which sought to increase inbound foreign students, was organized in 2004. And in 2009, the "World Class University Project" was initiated to cultivate universities of highest international recognition based on global rankings.

\subsection{The Brain Korea 21 and the World Class University Projects}

In 1999, the largest reform project in higher education was initiated by the Korean Ministry of Education and Human Resource Development (MoE): the "Brain Korea 21" (BK21) project. The BK21 project aimed to generate internationally competitive research universities and graduate programs while enhancing regional-industry based universities through the use of government funding. The BK 21 programs have undergone several phases. In BK21 Phase I, from 1999 to 2005, the project allocated US\$1.4 billion in funding for universities. In BK21 Phase II, from 2006 to 2012, US\$2.1 billion was granted to qualified participants. The "BK21 PLUS", launched in 2013, succeeded the original BK21 program and has been projected to continue through 2019. During the BK21 Phase II period, another independent program entitled the "World Class University Project" (WCU Project) was undertaken from 2008 to 2013 to establish leading universities mainly through attracting world-class faculties (Shin, 2009).

Under the vision of "stronger with enhanced human capital," the BK21 Phase I project set three overall objectives: "first, to foster world-class research universities which function as infrastructure in producing primary knowledge and technology, and promoting specialization of local universities; second, to introduce professional graduate schools in order to cultivate professionals in various fields; and third, to transform the higher education system in order to facilitate competitive growth among universities based on the quality of their students and academic productivities" (Moon \& Kim, 2001). To fulfill such objectives, participating universities were required to reform systems (e.g., admissions, management, faculty evaluation, curricula) against standards set by global elite universities (Shin, 2009). Designated universities were required to meet the necessary criteria for annual performance evaluations in order to receive continued government funding.

BK21 funding was granted to individual university departments or joint groups of departments (sa-up-dan). "Program-based" research funding was allocated by "academic discipline, geographical location, and scale of research group" (Korea Ministry of Education and Human Resource Development [MoE], 2006). The amount of funding was determined not by the programs but by the size of academic departments (Seong et al., 2008). The applicants, who met strict academic conditions, applied for programs among five sub-programs. Through competition in each sub-program, 67 universities with $\mathrm{PhD}$ programs were selected (Shin, 2009). The funding was granted as monthly scholarships and stipends to graduate students, postdoctoral scholars, and contract-based researchers. 89,366 participants in total—were benefitted over seven years—of which $60 \%$ were master's degree holders and 29\% were PhD degree holders (Korea Research Foundation, 2008). The universities were expected to select academic areas of concentration and contribute to reforming the areas by investing in infrastructure to ultimately increase global competitiveness (Seong et al., 2008).

As a result of the BK21 Phase I project, substantial advancement of research capacities resulted (Korea Research Foundation, 2008). The overall number of articles in science and technology listed on Science Citation Index (SCI) increased from 3,765 in 1998 to 7,281 in 2005, and the SCI national ranking of Korea advanced from 18th 
in 1998 to 12th in 2005. The number of papers in the humanities and social sciences published in nationwide journals also increased. Moreover, 2,800 graduate students participated in long-term (exceeding two months) research projects in leading HEIs, and 56,700 students in short-term projects. 6,000 renowned scholars from abroad were invited to Korea, furthering the development of global perspectives and international collaboration (Korea Research Foundation, 2008).

BK21 Phase II in 2006 had similar objectives of nurturing internationally competitive talents by establishing global research universities. The overall conditions were consistent to those of BK21 Phase I, but subtle differences could be identified. The ultimate objective remained to "nurture creative research manpower for the future and foster research universities specialized in specific academic discipline" (Seong et al., 2008). While BK21 Phase I focused on university-level excellence, BK21 Phase II emphasized department-level excellence, guided by Korea's Ministry of Education, Science and Technology's (MoE) emphasis on the "specialization of universities." BK21 Phase II encouraged university-industry linkages and regional research and development (R\&D) clusters, whereas BK21 Phase I emphasized institutional reforms.

Under these consecutive BK21 programs, more than $60 \%$ of the total budget was allocated to graduate students as research scholarships (National Research Foundation of Korea [NRF], 2014). Although initially, 569 centers or research teams (sa-up-dan) from 74 universities were selected when the project was launched in 2006, after strict annual assessments based on a set of evaluation criteria and the principle of "selection and concentration" were put into effect, 500 centers or research teams from 67 universities remained at the end of 2012 (Korea Ministry of Education, Science and Technology [MoE], 2012). Approximately 20,000 graduate students and 500 researchers were financially assisted, and 7,000 faculty participated in the programs. In the final evaluation of BK21 Phase II undertaken in 2013, teams were evaluated based on the achievement of specified goals and assessment of whether performance regulations were abided by. Numerous achievements, especially in the overall SCI impact factor were demonstrated; however, the overall evaluations of both the BK21 Phase I and Phase II projects remained controversial.

"The Brain Korea 21 Program for Leading Universities and Students" (BK21 PLUS) was launched in 2013 with the view that the former BK21 projects had limitations on the quality of research, institutional autonomy, and strategic internationalization. The new human resource development project aimed to nurture Master's and $\mathrm{PhD}$ students who could lead in the "creative economy" by enhanced research infrastructures (NRF, 2013). The primary objectives included expanding research capacities in converged fields such as new technology, cultural or social sciences with originality, and cultural contents that would play a leading role in generating a "guidance-style economy." Moreover, BK21 PLUS focused on strengthening the role of universities as hubs of creativity and innovation. While the overall objectives of the BK21 PLUS program were similar to that of previous projects, the most recent BK21 PLUS project actively encouraged the generation of creative talents in converged academic fields that would contribute to a creative economy and ultimately impact the number of HEIs in the global rankings to rank within the top 200 universities.

Another project that specifically focused on the establishment of globally-competitive universities was the "National Project toward Building World-Class Universities" from 2008 to 2013. The overarching goal was to promote research in core areas, notably fields related to the basic sciences, new industry creation and knowledge-based services, and to cultivate future academic generations (Seong et al., 2008). One of the goals of the WCU Project was to strengthen the collaboration among international scholars in order to set up research networks that could potentially serve as catalysts for the establishment of world class departments, and subsequently, "world-class universities." (Lee, 2012). It was initiated, in part, to enhance the internationalization of higher education along with the "Study Korea Project." While the BK21 projects provided abundant resources, the WCU Project was seen to have mobilized a wider array of talented students and researchers (Byun, Jon, \& Kim, 2013).

\subsection{Building of WCUs in Korea}

The rationale for Korea to establish WCUs revolved around the notions of creating economic value through the advancement of competitiveness in higher education, and promoting further internationalization by becoming involved in global knowledge networks. Consequently, the creation of WCUs has served as an important initiative for Korea, which views the development of higher education as a way by which it could become a highly developed country with increased international stature.

The WCU Project extended to three major areas of advancement: first, to create new divisions or departments with full-time foreign scholars; second, to enhance research collaboration with full-time foreign scholars and their teaching in existing divisions; and third, to invite non full-time foreign scholars and enhance research 
collaborations. A total of US\$750 million was invested during a span of six years, of which $70 \%$ was allocated in the first category of support. Numerous outcomes were generated in terms of SCI publications, research awards and acknowledgements, increased English curricula, and participants' overall satisfaction (Byun et al., 2013).

Various factors have allowed for the accelerated establishment of WCUs in Korea. At the forefront, the establishment of WCUs has been led by the government as a national directive. Due to the lack of both public funds and private investments, private universities in Korea, where approximately $80 \%$ of university students matriculate, rely heavily on high tuition rates (Altbach \& Salmi, 2011). Korean higher education follows the model of post-Confucian systems that feature "strong state steering and control over higher education's development, and individual commitment to self-cultivation through learning" (Wang, Cheng, \& Liu, 2012). The Korean government has chosen a strategy of "selection and concentration" to manage budgetary constraints, favoring high-performing universities (Albach \& Salmi, 2011). Strategic resource allocation has allowed not only prestigious public universities, such as Seoul National University and Korea Advanced Institute of Science and Technology (KAIST), but also elite private universities such as Pohang University of Science and Technology (POSTECH), Yonsei University and Korea University to advance toward becoming recognized WCUs in Korea.

The establishment of WCUs and higher education reforms is consistent with the Korean government's overall higher education policy. A key policy under President Myung-Bak Lee, who was inaugurated in 2008, was the implementation of the "powerhouse of talents" (In-jae-dae-guk), with the main objective of developing Korea into an advanced nation (Lee, 2012). "The talented" were defined as self-directed individuals who possess the creativity, as well as problem solving and communication skills necessary for fostering economic growth and social development within a knowledge-based society (Lee, 2012). Accordingly, the MoE established four systematic strategies for nurturing global talents, with a special focus on the fields of science and technology. The strategies included: creating an educational system for all that assures no students/talents are overlooked; second, fostering global talents with creativity and character; third, undertaking higher educational reform as a step toward a fully developed nation; and fourth, establishing a science and technology renaissance through creativity and convergence in R\&D (Lee, 2012). The reality of Korea's relatively small scale economy, population, government budget, $R \& D$ (industry-academia collaborative linkages), and the number of researchers was reflected in the national strategy that emphasized qualitative approaches rather than focusing on solely quantitative output measures.

The process by which WCUs and other higher education reforms in Korea were established followed the general global strategy of higher education reform. The government accentuated the role of "world-class research universities" as education was thought to nurture the talents of creativity and convergence, which would in turn create new technology to enhance national competitiveness (Lee, 2012). Ultimately, WCUs were to function as a driving force for the comprehensive development of Korea. Given the linkage between national strategy and the role of HEIs, the necessity to foster WCUs was formally recognized. The efforts to build WCUs and integrate higher education reforms in Korea were therefore established with the objective of cultivating higher education against global standards.

\subsection{Evaluation of Projects}

The series of national projects facilitated by Korea in the realm of higher education contributed heavily to the fostering of global research universities and competitive talents in specialized academic fields. However, it remains controversial as to whether the resulting effects were proportionate to the expected outcomes. Critics of the national projects have stressed the perceived negative aspects including the actual effectiveness of the projects on achieving the national objectives.

One of the main limitations focused on the discriminatory selection process of universities that had the effect of undermining the balanced development of Korean HEIs. Moon and Kim (2001) state that the BK21 projects chose "efficiency of investment over equal opportunity." The principle of "selection and concentration" of government policies gave advantage to select HEIs which were better equipped and qualified from the start. Nearly half of the entire budget of the BK21 and WCU Projects provided funding to five leading universities: SNU, KAIST, Yonsei University, Korea University and POSTECH (Byun et al., 2013). Less-financed universities and non-selected universities demonstrated a lack of research facilities and students which undermined their competitiveness. Institutions that were granted substantial amounts of funding were mostly located in the Seoul metropolitan area and drew regional talents into the capital.

Other criticisms included the limited areas of research concentration, with virtually all projects focused on specialized fields. Nearly $75 \%$ of the BK 21 projects and $88 \%$ of the WCU Project funding were focused on 
research and study in the fields of science and technology. Project funding supported highly-ranked universities to focus on specialized areas, which accounted for more than $80 \%$ of the BK21 projects and $93 \%$ of the WCU Project funding, and such uneven distribution of funding caused other basic academic fields to lag behind in research and development (Byun et al., 2013).

The quantification of scholarship and research suggested other hindrances to the overall success of these projects. Strategies employed to meet project goals were based on quantitative measures, including the number of publications listed in the SCI, the number of international students and faculty, the percentage of English-medium courses, and improved overall global rankings. Such quantitative approaches could arguably have come at the expense of the quality of the outcome and may have even damaged the long-term growth potential of the Korean higher education system. For instance, since published works in English-based journals are accompanied by greater awards and recognition, the goal of getting published in such journals may have impeded the original objectives of research such as addressing scholarly inquiries and promoting innovation (Byun et al., 2013). This concern was acknowledged by the MoE, and was addressed in the BK21 PLUS project in 2013, by emphasizing the role of universities as sources of creativity and innovation. In addition, institutional reforms of HEIs produced other repercussions in matriculation rates at top institutions. Due to the reduction in the number of undergraduate and graduate students admitted through the BK21 project grants, admissions to heavily funded graduate programs became increasingly competitive in an already overly-heated admissions environment.

Problematic issues regarding academic autonomy and freedom were also raised as important issues by many scholars and administrations within HEIs. This phenomenon can be interpreted through the theoretical framework of "resource dependency." As the Korean government budget was highly concentrated on higher education reform projects, universities became dependent on such government funding. In the midst of scarce resources, large government fundings became critical to universities in realizing institutional objectives. HEIs were required to incorporate the guidelines and conditions of the MoE in order to receive such funding which were considered to have restricted institutional autonomy (Kim \& Nam, 2007).

The discourse of normalization provides yet another framework in interpreting the limitations of national projects. Critics have highlighted concerns that HEIs in Korea have adopted indicators without proper contextualization. The MoE implicitly presupposed that the ideal model of HEIs was an Anglo-Saxon research university, particularly that of the United States. Korean universities were inadvertently emulating the U.S. educational model in terms of curriculum and language, and HEIs were promoting partnerships primarily with universities in English-speaking countries, which potentially precluded the development of an independent and visionary tertiary educational system (Byun et al., 2013). Recognizing that the widely used "global standards" were tailored around the model of American/European universities, Westernized standards became the accepted norms for Korean universities.

Nonetheless, the quantitative outcomes of major Korean universities demonstrated a rapid upward trajectory on the QS World University Rankings. According to the QS World University Rankings (2007-2014), Seoul National University (SNU), Korea Advanced Institute of Science and Technology (KAIST), Pohang University of Science and Technology (POSTECH), Yonsei University and Korea University raised their overall rankings through the years of 2007 to 2012. All institutions ranked in the top 200 beginning in 2010. In 2009, the QS in partnership with The ChosunIlbo, a major Korean newspaper, created the QS University Rankings: Asia which independently ranked universities within Asia. Although based on similar criteria as the QS World University Rankings, different weightings and additional criteria ranked universities in the rapidly growing Asia-Pacific region. In the QS University Rankings: Asia since 2009, the four leading universities in Korea have been ranking in the top-20s within the region (QS University Rankings: Asia, 2009-2014). However, even with both the QS World University Rankings and the QS University Rankings: Asia, controversies still exist regarding the reliability of the rankings, with subjective criteria, such as "peer-review" accounting for a distinct portion of overall evaluations. According to Altbach (2012), "The QS World University Rankings are the most problematical... [w] hether the QS rankings should be taken seriously by the higher education community is questionable."

Lastly, Jang and Kim (2013) examine the broken "value consensus" related to the establishment of WCUs and other government initiated projects such as the BK21 projects. While Korean academics emphasized "power" and "control" in educational decision-making and highlighted the importance of quantity-oriented evaluations, foreign scholars were more focused on the recipients, "the students," who were designated to be the beneficiaries of the enhanced value of higher education (Jang \& Kim, 2013). This cleavage in perception implies that policy makers and local academics overlooked the ultimate objectives of establishing globally competitive HEIs and the undertaking of other HEIs reforms, which eventually caused discord among local and foreign academics. 
Moreover, the Korean bureaucracy, stifling management structures, and cultural differences were identified as other significant factors that hampered increased research collaboration between local and foreign academics. Sharply opposing evaluations of the Korean national projects have implications on future higher education reform and the current standings of the Korean HEIs.

\section{Conclusion: Prospects and Recommendations}

Korea's efforts to establish globally-competitive HEIs and WCUs adhering to global standards are generally perceived, both domestically and internationally, as successful national undertakings. The implications of global university rankings are expected to expand as well as further the internationalization of higher education in Korea. Accordingly, the interest in and importance of building domestic prestigious universities that are recognized by the international community will continue to grow.

With anticipated drawbacks and criticisms, however, it is necessary to re-evaluate the overall direction of Korean policies to the further the promotion of WCUs and other government initiated projects and incorporate lessons from the past to initiate future policies. Marginson (2011) explains that East Asian countries, including Korea, have distinctive cultural and political backgrounds against which educational institutions have been fostered. He notes that post-Confucian countries show high commitment to tertiary education at the household level since meritocracy, which utilized the method of scholarly examination for bestowing political status, was prevalent in the Confucian society. Traditional notions and cultural characteristics of Confucian societies have been highly reflected in the government-initiated building of research universities in East Asian societies. In the Korean context, the government has spearheaded the "excellence initiatives" by allocating extensive funding to state-directed projects in the higher education sector. The model of state-led education projects is strikingly distinct from those of Western countries where tertiary institutions receive a large degree of investments and funding from other public and private sources. In sum, the Korean government has utilized and incorporated the existing background of higher education to fuel the successful implementation of higher education projects and reforms.

However, the flaws in the global criteria of WCUs and globally-ranked HEIs that Korea has adopted have generated critical reviews from both domestic and foreign audiences. Mohrman (2009) clearly identifies five characteristics of the "American model" of WCUs that indigenous universities should avoid adopting in the building of WCUs. First, the prevalent model of WCUs imposes a uni-dimensional definition of quality, which revolves around "research performance." Second, publication generation is perceived as the only legitimate form of scholarship. Third, rankings are used as primary tools that define excellence. Fourth, large-scale and well-endowed universities are preferred as funding recipients. Lastly, government financial assistance is over-allocated to HEIs rather than to other sectors. Numerous examples demonstrate how such criteria have been reflected on Korean higher educational reform.

Of the measures of quality of HEIs, the quantitative measure of research output continues to dominate Korean universities' strategies to raise their profiles both domestically and internationally. At the expense of fostering comprehensive developments within the university sector, the pressures on Korean universities to generate published research output remain unabated. As publication generation is generally accepted as the primary form of scholarship in higher education, scholars in Korea refrain from experimenting with other forms of research and inquiry that do not result in tangible research output. While attaining higher global rankings constitutes overarching objectives for many Korean universities, more qualitative approaches to achieving "global norms" in important areas of tertiary education, such as teaching and mentorship, should be reinforced as important agendas in higher education reform.

Highly concentrated government funding to select top-tiered universities has generated unprecedented controversies of unbalanced distribution in the higher education sector. The roles and important contributions of alternate types of universities (i.e., regional universities) and specialized departments need to be further integrated into the higher education scheme. More generally, Korea should set feasible goals in terms of national capacity and needs. It is often noted by scholars that not many WCUs and highly specialized HEIs are needed nor desirable for certain countries, primarily due to the high costs to a nation (Altbach, 2004). As Korea diversifies its support to public and private universities, less dependency on government funding and more independent planning for comprehensive development within the higher education sector should be strived for.

The concept of WCUs and globally-ranked HEIs in Korea is a byproduct of a complex geography in the global higher educational system. Excellence initiatives implemented by the Korean government, such as the BK21 projects and the WCU Project, have transformed Korean HEIs to be more attuned to global norms of top universities. Korea has attracted qualified talents and academics from around the world, has restructured the 
tertiary education system, and has improved the overall level of higher education. The government-initiated projects have been highly acclaimed by many, and have been regarded as one of the most ambitious and successful commitments among national initiatives in education worldwide. Carefully re-adjusted strategies based on feasible and appropriate evaluation criteria that place importance on the context and uniqueness of Korean higher education are needed to ultimately improve national prestige and enable Korea to play a more active and unique role in the global settings of a new higher educational paradigm.

\section{References}

Altbach, P. (2004). The Costs and Benefits of World-Class Universities. Academe, 90(1), 20-23. http://dx.doi.org/10.2307/40252583

Altbach, P. (2012). The Globalization of College and University Rankings. Change, 44(1), 26-31. http://dx.doi.org/10.1080/00091383.2012.636001

Altbach, P., \& Salmi, J. (Eds.). (2011). TheRoad to Academic Excellence: The Making of World-Class Research Universities. Washington, DC: The World Bank. http://dx.doi.org/10.1596/978-0-8213-8805-1

Amsler, S. S., \& Bolsmann, C. (2012). University Rankings as Social Exclusion. British Journal of Sociology of Education, 33(2), 283-301. http://dx.doi.org/10.1080/01425692.2011.649835

Bloom, D. E., Hartley, M., \& Rosovsky, H. (2007). Beyond Private Gain: The Public Benefits of Higher Education. In International Handbook of Higher Education (pp. 293-308). Springer Netherlands.

Byun, K. (2008). New Public Management in Korean Higher Education: Is It Reality or Another Fad? Asia Pacific Education Review, 9(2), 190-205. http://dx.doi.org/10.1007/BF03026499

Byun, K., \& Kim, M. (2011). Shifting Patterns of the Government's Policies for theInternationalization of Korean Higher Education. Journal of Studies in International Education, 15(5), 467-486. http://dx.doi.org/10.1177/1028315310375307

Byun, K., Jon, J., \& Kim, D. (2013). Quest for Building World-Class Universities in South Korea: Outcomes and Consequences. Higher Education: The International Journal of Higher Education and Educational Planning, 65(5), 645-659. http://dx.doi.org/10.1007/s10734-012-9568-6

Cremonini, L., Westerheijden, D. F., Benneworth, P., \& Dauncey, H. (2014). In the Shadow of Celebrity: World-Class University Policies and Public Value in Higher Education. Higher Education Policy, 27, 341-361. http://dx.doi.org/10.1057/hep.2013.33

Gacel-Ávila, J. (2005). The Internationalisation of Higher Education: A Paradigm for Global Citizenry. Journal of Studies in International Education, 9(2), 121-136. http://dx.doi.org/10.1177/1028315304263795

Hazelkorn, E. (2008). Rising popularity of rankings. Campus Review, 27 May.

Hazelkorn, E. (2011). Globalization and the Reputation Race in Rankings and the Reshaping of Higher Education: the Battle for World Wide Excellence. Palgrave MacMillan. http://dx.doi.org/10.1057/9780230306394

Hazelkorn, E. (2013). World-Class Universities or World-Class Systems? Rankings and Higher Education Policy Choices. In E. Hazelkorn, P. Wells, \& M. Marope (Eds.), Rankings and Accountability in Higher Education: Uses and Misuses. Paris: UNESCO.

Hood, C. (1989). Public Administration and Public Policy: Intellectual Challenges for the 1990s. Australian Journal of Public Administration, 48, 346-58. http://dx.doi.org/10.1111/j.1467-8500.1989.tb02235.x

Ishikawa, M. (2009). University Rankings, Global Models, and Emerging Hegemony: Critical Analysis from Japan. Journal of Studies in International Education, 13(2), 159-173. http://dx.doi.org/10.1177/1028315308330853

Jang, D. H., \& Kim, L. (2013). Framing 'World Class' Differently: International and Korean Participants' Perceptions of the World Class University Project. Higher Education: The International Journal of Higher Education and Educational Planning, 65(6), 725-744. http://dx.doi.org/ 10.1007/s10734-012-9573-9

Jöns, H., \& Hoyler, M. (2013). Global Geographies of Higher Education: The Perspective of World University Rankings. Geoforum, 46, 45-59.

Kim, A. E. (2010). Problems and Implications of Korea's Ageing Population. Panorama: Insights into Asian and European Affairs is a series of occasional papers published by the Konrad-Adenauer-Stiftung's "Regional Programme Political Dialogue Asia/Singapore.”, 2019(2026), 157. 
Knight, J. (2002). Trade in Higher Education Services: The Implications of GATS. The Observatory on Borderless Higher Education, UK. http://dx.doi.org/10.1023/A:1016330531437

Korea Ministry of Education and Human Resource Development (MoE). (2006). Year 2006, Basic Managerial Plan for Phase II BK21 Program. September, 2006.

Korea Ministry of Education, Science and Technology. (2012). Implementation of the Overall Evaluation on the Brain Korea 21 Project Phase II. News Release 18 January, 2012.

Lee, J. H. (Ed.). (2012). Positive Changes: The Education, Science \& Technology Policies of Korea. The Korea Economic Daily, Seoul.

Mergner, J. (2011). Internationalization Strategies in South Korean higher education-An Explanatory Analysis of the Internationalization Efforts of Four Korean Universities through the Lenses of Resource Dependency and Normative Match. Retrieved from http://purl.utwente.nl/essays/62822

Moon, M., \& Kim, K. S. (2001). A Case of Korean Higher Education Reform: The Brain Korea 21 Project. Asia Pacific Education Review, 2(2), 96-105. http://dx.doi.org/10.1007/BF03026294

Organization for Economic Co-operation and Development (OECD). (2007). OECD database 2007. Retrieved December 30, 2014, from http://www.oecd.org/document/54/0,3343,en_2649_37455_38082166_1_1_1_ $37455,00 . \mathrm{html}$

Park, H., \& Kim, K. K. (2014). Korean Education in Changing Economic and Demographic Contexts. Springer. http://dx.doi.org/10.1007/978-981-4451-27-7

Pollitt, C. (1993). Managerialism and the Public Services: The Anglo-American Experience (2nd ed.). Blackwell, Oxford.

Robertson, S. (2008). Producing Knowledge Economies: The World Bank, the KAM, Education and Development. Re-reading Education Policies: Studying the Policy Agendas of the 21st Century. Dortrecht: Sense Publishers.

Robertson, S. L. (2012). World-Class Higher Education (for whom?). Prospects, 42(3), 237-245. http://dx.doi.org/10.1007/s11125-012-9236-8

Sadlak, J. (2009). The World-Class University as Part of a New Higher Education Paradigm: From Institutional Qualities to Systemic Excellence. UNESCO-CEPES.

Salmi, J. (2009). The Challenge of Establishing World-Class Universities. World Bank Publications.

Seong, S., Popper, S. W., Goldman, C. A., \& Evans, D. K. (2008). Brain Korea 21 Phase II: A New Evaluation Model. Rand Corporation.

Shin, J. C. (2009). Building World-Class Research University: The Brain Korea 21 Project. Higher Education, 58(5), 669-688. http://dx.doi.org/10.1007/s10734-009-9219-8

Symonds, Q. (2007-2013). QS World University Rankings. Retrieved from http://www.topuniversities. com/qs-world-university-rankings

Symonds, Q. (2009-2014). QS University Rankings: Asia. Retrieved from $\mathrm{http}: / / \mathrm{www}$.topuniversities.com/university-rankings/asian-university-rankings

The World Class University Since 2008. (2014). The World Class University Since 2008, Objectives. Retrieved July 27, 2014 from http://wcu.nrf.re.kr/info/info002.jsp.

United Nations Educational, Scientific and Cultural Organization (UNESCO). (1998). World Conference on Higher Education: Higher Education in the Twenty-First Century Vision and Action. Final Report (1). 1998, 5-8 October UNESCO Paris.

Wacquant, L. (1993). From ruling class to field of power: Interview with Bourdieu. Theory, Culture and Society, 10, 19-44. http://dx.doi.org/10.1177/026327693010003002

Wang, Q., Cheng, Y., \& Liu, N. C. (2013). Building World-Class Universities: Different Approaches to a Shared Goal (Vol. 25). Springer Science \& Business Media. http://dx.doi.org/10.1007/978-94-6209-034-7 


\section{Copyrights}

Copyright for this article is retained by the author(s), with first publication rights granted to the journal.

This is an open-access article distributed under the terms and conditions of the Creative Commons Attribution license (http://creativecommons.org/licenses/by/3.0/). 